\title{
Treatment with cinacalcet decreases systolic blood pressure in haemodialysed patients with chronic kidney disease and secondary hyperparathyroidism
}

\author{
Piotr Kuczera, Marcin Adamczak, Andrzej Wiecek \\ Department of Nephrology, Transplantation and Internal Medicine, Medical University of Silesia, Katowice, Poland
}

\section{Summary}

Background There are numerous evidences suggesting that parathyroid hormone (PTH) plays a role in the pathogenesis of arterial hypertension. Treatment with cinacalcet decreases serum PTH concentration in haemodialysed patients with chronic kidney disease (HDP) and secondary hyperparathyroidism (sHPT) Chronic kidney disease is a pro-inflammatory state. The aim of this study was therefore to assess the influence of 6-month treatment with cinacalcet on blood pressure (BP) and inflammation markers in HDP with sHPT.

Material and methods In 58 HDP with sHPT serum PTH, interleukin-6, C-reactive protein, calcium and phosphate concentrations were assessed before the first dose of cinacalcet and after 3 and 6 months of treatment. BP was measured before haemodialysis sessions.

Results Serum PTH concentration decreased significantly after 3 and 6 months of cinacalcet treatment from 1138 (931-1345) to 772 (551-992); $\mathrm{p}<0.0001$ and to 635 (430-839) pg/ml; $\mathrm{p}<0.0001$, respectively. Systolic BP decreased after 3 and 6 months of treatment from 128 (123-133), to $125(120-131)$ and to $121(115-127) \mathrm{mm} \mathrm{Hg}$, respectively ( $\mathrm{p}$ for trend $=0.014$ ). Diastolic BP did not change significantly. There were no significant differences in the number of antihypertensive drugs, vitamin $\mathrm{D}$ analogues dose and patients' body weight, nor the serum concentrations of IL-6 and CRP during the treatment period.

Conclusions 1. Six-month treatment with cinacalcet decreases systolic BP in haemodialysed patients with chronic kidney disease and secondary hyperparathyroidism. 2. The elucidation of exact pathomechanism of such a BP decrease needs further clinical studies, but it seems not to be related to inflammatory status changes.

key words: chronic kidney disease, secondary hyperparathyroidism, cinacalcet, blood pressure, haemodialysis Arterial Hypertens. 2015, vol. 19, no. 3, pages: 129-134

DOI: $10.5603 / A H .2015 .0016$

\section{Background}

Secondary hyperparathyroidism (sHPT) is among the most common abnormalities in haemodialysed patients with chronic kidney disease (CKD). The aetiopathogenesis of sHPT in CKD patients is complex and still not fully understood. Nevertheless, it can be generally summed up as the excessive parathormone (PTH) secretion caused by hyperphosphataemia, hypocalcaemia and low vitamin D status [1,2].

PTH is regarded as one of the uraemic toxins and is one of the factors contributing to the pathogenesis of hypertension, which was documented in experi-

Address for correspondence: Andrzej Więcek, MD, PhD

Department of Nephrology, Transplantation and Internal Medicine, Medical University of Silesia

ul. Francuska 20/24, 40-027 Katowice, Poland

tel.: +48-322552695; fax: +48-322553726; e-mail: awiecek@spskm.katowice.pl 
mental studies [3], as well as in clinical studies conducted among others in maintenance haemodialysis (HD) patients $[4,5]$. Moreover PTH seems to be associated with the increased cardiovascular burden in $\mathrm{HD}$ patients, in earlier stages of CKD as well as in general population [6-10].

Cinacalcet is a type II calcimimetic. Such compounds bind to the calcium receptor $(\mathrm{CaR})$, which results in its increased sensitivity to serum calcium. This leads to the decrease of parathormone (PTH) production by the parathyroid glands $[11,12]$. Cinacalcet is now commonly used in the treatment of secondary hyperparathyroidism in haemodialysed CKD patients. In the ACHIEVE study combined cinacalcet and small dose vitamin $\mathrm{D}$ treatment showed greater reduction in the progression of vascular and heart valve calcification compared to vitamin $\mathrm{D}$ alone [13-15].

Multiple lines of evidence suggest that PTH may be involved in the pathogenesis of hypertension. It has been shown that the excess serum PTH concentration in uraemia leads to the increase of calcium content in many cells and tissues (among them in blood vessels [16] and heart [17]). Results of animal experiments suggest that parathyroidectomy in 5/6 nephrectomised rats improved the endothelial dysfunction (normalized the synthesis of nitric oxide by the endothelial cells) [18]. Similar results were obtained from the clinical studies. Serum PTH concentration was found to be an independent predictor of the new-onset hypertension [19], as well as the left ventricle hypertrophy [20]. Moreover, parathyroidectomy causes the blood pressure decrease in patients with primary hyperparathyroidism [22].

It is well known that chronic kidney disease is a pro-inflammatory state. The results of recent studies have shown that the serum concentrations of markers of inflammation are significantly elevated in CKD patients [23-25]. Moreover, it was found that the extent of inflammation (measured by the neopterin concentration) is inversely related to the eGFR [26].

It has been shown that circulating PTH may stimulate the secretion of IL-6 in osteoblasts. This may be the cause of the elevated serum IL- 6 concentration in secondary as well as in primary hyperparathyroidism. IL-6 is one of the main stimulants of the elevated synthesis of the so called acute phase proteins (e.g. CRP and fibrinogen) in the liver [27-29].

Taking into consideration the fact that PTH substantially contributes to the development of hypertension, it was reasonable to study the influence of 6-month cinacalcet treatment on blood pressure in haemodialysed patients with CKD and sHPT.
Moreover, since PTH may induce IL-6 synthesis and cinacalcet reduces serum PTH concentration and taking into account the contribution of the inflammatory status in the pathogenesis of hypertension [32], it was interesting to assess the influence of cinacalcet on the blood pressure in in these patients.

\section{Materials and methods}

Seventy-one adult, haemodialysed CKD patients (40 males, 31 females) with sHPT (defined as serum PTH concentration $>300 \mathrm{pg} / \mathrm{ml}$ ) recruited from 9 different haemodialysis centres were enrolled in this clinical, prospective, open-label, single-arm study. Mean age of patients was $53.3 \pm 14.8$ years, median time of renal replacement therapy was 32 months [interquartile range (IQR) -28 months]. Exclusion criteria were: age below 18 years, severe liver insufficiency, oversensitivity to any of the study drug compounds, high probability of non-compliance and suspected short life expectancy on renal replacement therapy.

Patients were treated with cinacalcet. Initial dose was $30 \mathrm{mg}$ once daily and was modified, if needed, every 4 weeks depending on the serum PTH concentration. The target of treatment was to decrease serum PTH concentration to $150-300 \mathrm{pg} / \mathrm{ml}$. Maximal dose of cinacalcet was $120 \mathrm{mg}$ daily.

The doses of calcium carbonate and vitamin D analogues were flexible in order to avoid cinacalcet related hypocalcaemia and hypophosphataemia. Aluminium hydroxide was only used as a temporary "rescue" therapy in patients with severe hyperphosphataemia.

In every patient, plasma serum PTH (electrochemiluminescence; Roche, Mannheim, Germany), interleukin-6 (ELISA; R\&D Systems, Abingdon, UK), C-reactive protein (ELISA; Immunodiagnostic AG, Bensheim, Germany), calcium and phosphate (Beckman Coulter UniCel DXC 600 analyser) concentrations were assessed before the first dose of cinacalcet and then after 3 and 6 months of treatment. Blood samples were collected before haemodialysis procedure in the middle of the week. After collection, blood samples were centrifuged, serum was aliquoted in $1 \mathrm{ml}$ test-tubes and then rapidly frozen in $-70^{\circ} \mathrm{C}$.

Moreover, in each patient arterial blood pressure was assessed on the brachial artery. The measurement was conducted before three consecutive haemodialysis sessions preceding the blood samples collection.

Statistical analyses were performed using the Statistica 10.0 PL software (StatSoft Polska, Cracow, Poland). Shapiro-Wilk test was used to test the variables distribution. Repeated measures ANOVA with 
Bonferroni's correction for multiple comparisons, or alternatively Wilcoxon matched pairs test were used to assess the longitudinal changes of variables. Correlation coefficients were calculated using Spearman's rank correlation.

Results are shown as means with 95\% confidence interval (CI), or as means with standard deviation, alternatively as median values with interquartile range (IQR) for variables with skewed distribution. Differences were considered significant when $p<0.05$. The study protocol, adherent to Declaration of Helsinki, was approved by the Medical University of Silesia Bioethics Committee (KNW/0022/KB1/56/I/10 21.09.2010) and all patients gave their written informed consent for participation in the study.

\section{Results}

From 71 enrolled patients, 58 (35 males, 23 females, mean age $53.8 \pm 14.9$ years) completed the study. Thirteen patients were ruled out of the study; among them 4 people died, 2 received kidney allograft, 2 patients discontinued the study because of permanent decrease of serum PTH concentration below $150 \mathrm{pg} / \mathrm{ml}$, 2 underwent parathyroidectomy, one patient refused to continue the study due to paraesthesia; one patient withdrew the consent for the study and one moved out of the Silesian province.

The mean doses of cinacalcet after 3 and 6 months of treatment were $42 \pm 17 \mathrm{mg}$ and $51 \pm 23 \mathrm{mg}$ respectively. The doses of intestinal phosphate binders and active vitamin $\mathrm{D}_{3}$ analogues were flexible in order to avoid hypocalcaemia and hypophosphataemia related to cinacalcet treatment. The percentage of pa- tients treated with vitamin $\mathrm{D}$ analogues (alfacalcidol) and mean daily dose of alfacalcidol increased from $0.26 \mathrm{mg}(0.17-0.36 \mathrm{mg})$ at the baseline, to $0.39 \mathrm{mg}$ $(0.25-0.52 \mathrm{mg})$; ( $\mathrm{p}$ for trend $=0.04$; Table 1$)$. Moreover, there was a significant ( $p$ for trend $=0.01$ ) decrease in the mean dose of aluminium hydroxide (Alusal) from $385 \mathrm{mg} /$ day $(170-410 \mathrm{mg} /$ day) at the baseline, to $180 \mathrm{mg} /$ day $(15-350 \mathrm{mg} /$ day) after 6 months of treatment. The number of patients treated with aluminium hydroxide also decreased (Table 1). The mean dose of calcium carbonate and the number of patients treated with this drug remained stable (Table 1).

In patients who completed the study cinacalcet treatment caused significant decrease of serum PTH from $1138 \mathrm{pg} / \mathrm{ml}(931-1345 \mathrm{pg} / \mathrm{ml})$ at the baseline, to $772 \mathrm{pg} / \mathrm{ml}(551-992 \mathrm{pg} / \mathrm{ml})$ after 3 month of treatment, and to $635 \mathrm{pg} / \mathrm{ml}(430-839 \mathrm{pg} / \mathrm{ml})$ after 6 months of treatment ( $p$ for trend $<0.0001$; Table 2). The mean decrease of serum PTH concentration after 3 and 6 months of treatment was $32.2 \%$ and $44.2 \%$, respectively.

Six months of treatment with cinacalcet was associated with a significant $(p$ for trend $=0.014$ ) reduction of the mean systolic blood pressure from $128 \mathrm{~mm} \mathrm{Hg}(122-133 \mathrm{~mm} \mathrm{Hg})$ at the baseline to $125 \mathrm{~mm} \mathrm{Hg}(120-131 \mathrm{~mm} \mathrm{Hg})$ after 3 months and $123 \mathrm{~mm} \mathrm{Hg}(118-128 \mathrm{~mm} \mathrm{Hg})$ after 6 months. There were no significant ( $\mathrm{p}$ for trend $=0.14$ ) differences in the diastolic blood pressure: $76 \mathrm{~mm} \mathrm{Hg}$ (73-79 $\mathrm{mm} \mathrm{Hg}), 76 \mathrm{~mm} \mathrm{Hg}(73-79 \mathrm{~mm} \mathrm{Hg})$ and $75 \mathrm{~mm} \mathrm{Hg}(71-77 \mathrm{~mm} \mathrm{Hg})$ - Figure 1.

In the entire study group there were no significant differences in the mean serum calcium and phosphate concentration during cinacalcet treatment

Table 1. Doses of alfacalcidol, intestinal phosphate binders and the number of patients using those drugs during cinacalcet treatment

\begin{tabular}{|c|c|c|c|c|}
\hline & Before treatment & $\begin{array}{l}\text { After } 3 \text { months of } \\
\text { treatment }\end{array}$ & $\begin{array}{l}\text { After } 6 \text { months of } \\
\text { treatment }\end{array}$ & $p$ for trend \\
\hline $\begin{array}{l}\text { Dose of alfacalcidol } \\
{[\mu \mathrm{g} / 24 \mathrm{~h}]}\end{array}$ & $\begin{array}{l}0.26 \\
(0.17-0.36)\end{array}$ & $\begin{array}{l}0.32 \\
(0.2-0.44)\end{array}$ & $\begin{array}{l}0.39^{*} \\
(0.25-0.52)\end{array}$ & 0.04 \\
\hline Number of patients treated with alfacalcidol & $30(52 \%)$ & $34(59 \%)$ & $40(69 \%)$ & 0.06 \\
\hline $\begin{array}{l}\text { Dose of } \mathrm{CaCO}_{3} \\
{[\mathrm{~g} / 24 \mathrm{~h}]}\end{array}$ & $\begin{array}{l}3.49 \\
(2.68-4.30)\end{array}$ & $\begin{array}{l}3.84 \\
(2.95-4.72)\end{array}$ & $\begin{array}{l}3.88 \\
(3.04-4.72)\end{array}$ & 0.053 \\
\hline Number of patients treated with $\mathrm{CaCO}_{3}$ & $53(91 \%)$ & $55(95 \%)$ & $54(93 \%)$ & 0.71 \\
\hline $\begin{array}{l}\text { Dose of aluminium hydroxide } \\
\text { [mg/24h] }\end{array}$ & $\begin{array}{l}385 \\
(170-605)\end{array}$ & $\begin{array}{l}310 \\
(80-540)\end{array}$ & $\begin{array}{l}180^{*} \\
(15-350)\end{array}$ & 0.01 \\
\hline Number of patients treated with aluminium hydroxide & $12(21 \%)$ & $8(14 \%)$ & $5(9 \%)$ & 0.06 \\
\hline
\end{tabular}




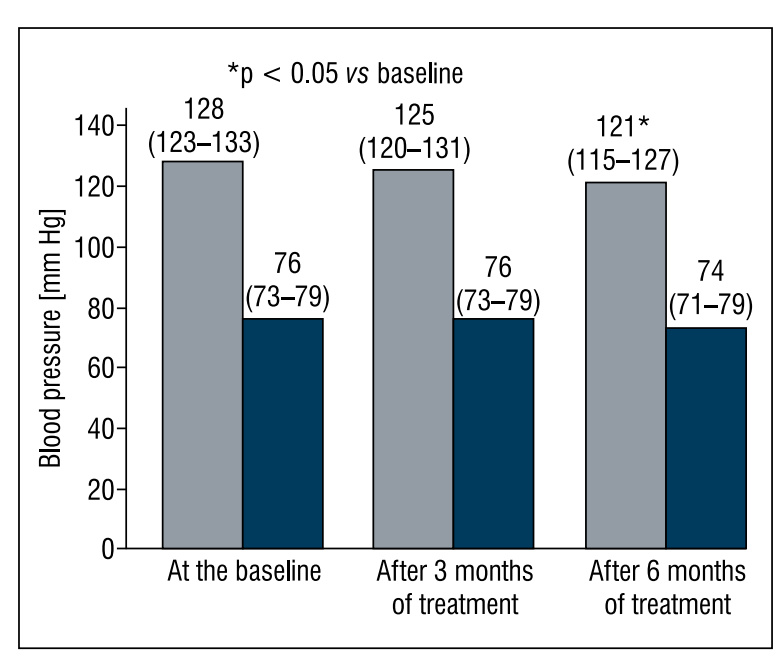

Figure 1. The changes of blood pressure during 6 months of cinacalcet treatment nacalcet was observed. There were no significant differences in the patients' diastolic blood pressure.

Treatment with cinacalcet was not associated with any significant changes of the serum concentration of inflammation markers - the concentrations of both CRP and IL-6 remained stable during the observation period.

Secondary hyperparathyroidism is characterized by, among others, the excess of PTH secretion and PTH is one of the factors contributing to the development of hypertension in maintenance haemodialysis patients [33], patients in pre-dialysis stages of CKD [34], as well as in general population [35, 36]. Nevertheless there's only one paper published so far concerning the influence of cinacalcet on blood pressure in the maintenance haemodialysis patients. In the secondary analyses of the EVOLVE

Table 2. The changes of serum parathormone, inflammation markers, calcium and phosphate concentrations during the treatment with cinacalcet

\begin{tabular}{|c|c|c|c|c|}
\hline & Before treatment & $\begin{array}{l}\text { After } 3 \text { months of } \\
\text { treatment }\end{array}$ & $\begin{array}{l}\text { After } 6 \text { months of } \\
\text { treatment }\end{array}$ & $p$ for trend \\
\hline $\begin{array}{l}\text { PTH } \\
{[\mathrm{pg} / \mathrm{ml}]}\end{array}$ & $\begin{array}{l}1138 \\
(931-1345)\end{array}$ & \begin{tabular}{|l|}
772 \\
$(551-992)$
\end{tabular} & $\begin{array}{l}635 \\
(430-839)\end{array}$ & $<0.0001$ \\
\hline $\begin{array}{l}\text { CRP } \\
{[\mathrm{mg} / \mathrm{l}]}\end{array}$ & $\begin{array}{l}11.2 \\
(9.2-13.1)\end{array}$ & $\begin{array}{l}11.6 \\
(9.4-13.7)\end{array}$ & $\begin{array}{l}10.5 \\
(8.6-12.4)\end{array}$ & 0.54 \\
\hline $\begin{array}{l}\text { IL-6 } \\
{[\mathrm{pg} / \mathrm{ml}]}\end{array}$ & $\begin{array}{l}5.76 \\
(4.77-6.75)\end{array}$ & \begin{tabular}{|l}
6.28 \\
$(5.11-7.45)$
\end{tabular} & $\begin{array}{l}5.72 \\
(4.76-6.68)\end{array}$ & 0.94 \\
\hline $\begin{array}{l}\mathrm{Ca} \\
{[\mathrm{mmol} / \mathrm{l}]}\end{array}$ & $\begin{array}{l}2.15 \\
(2.07-2.22)\end{array}$ & \begin{tabular}{|l}
2.11 \\
$(2.04-2.17)$
\end{tabular} & $\begin{array}{l}2.09 \\
(2.01-2.16)\end{array}$ & 0.15 \\
\hline $\begin{array}{l}\text { Phosphate } \\
\text { [mmol/l] }\end{array}$ & $\begin{array}{l}2.02 \\
(1.87-2.18)\end{array}$ & \begin{tabular}{|l|}
1.97 \\
$(1.80-2.14)$
\end{tabular} & $\begin{array}{l}1.89 \\
(1.73-2.05)\end{array}$ & 0.10 \\
\hline
\end{tabular}

${ }^{*} p<0.05$ vs baseline (Bonferroni corrected)

PTH - parathormone; CRP — C-reactive protein; IL-6 - Interleukin 6; SBP — systolic blood pressure; DBP — diastolic blood pressure

(Table 2). Also, the mean serum concentrations of inflammation markers (CRP and IL-6) did not change significantly during the observation period.

There were no significant correlations between the changes of serum concentrations of PTH and markers of inflammation, nor the changes of the aforementioned and the changes of blood pressure. Moreover there were no significant correlations between the changes of PTH, inflammation markers or blood pressure and the dose of alfacalcidol.

\section{Discussion}

In this multicentre prospective open-label single-arm clinical study a significant decrease of systolic blood pressure during the 6 months treatment with ci- trial Chang et al. found that 20 weeks treatment with cinacalcet resulted in a $2.2 \mathrm{~mm} \mathrm{Hg}$ decrease in systolic blood pressure and a $1.3 \mathrm{~mm} \mathrm{Hg}$ decrease in diastolic blood pressure when compared with placebo. This is partly in agreement with the results of current study, as we found a $5 \mathrm{~mm} \mathrm{Hg}$ decrease in the systolic blood pressure but no differences in the diastolic blood pressure after 6 months of treatment.

Similarly to the results of current and EVOLVE studies in patients after successful kidney transplantation the reduction of $\mathrm{BP}$ caused by the cinacalcet treatment was described [21].

In the study by Bonet et al. [37] the authors found no significant differences in central and peripheral blood pressure under a 12-month cinacalcet regimen, but they did describe a significant reduction of pulse wave velocity (PWV) and a decrease of 
left ventricle mass (borderline significance $\mathrm{p}=0.06$ ). The reduction of arterial stiffness and the decrease of the development of cardiovascular calcifications caused by the treatment with cinacalcet may be one of potential explanations of our findings, while the lack of differences in the central and peripheral blood pressure in the study by Bonet et al. might be, at least to a point, explained by the low number of enrolled participants. Also they assessed blood pressure in the day between dialysis procedures and we did the measurements directly before the HD session what may also contribute to the differences in the BP values.

Interestingly, there were no significant differences in PWV in patients on peritoneal dialysis treated with cinacalcet [38]. Nevertheless, the number of enrolled subjects was also low in this study (only 19) and cinacalcet failed to lower the serum PTH concentration in substantial number of these patients.

Another potential explanation of our findings may be the fact that $\mathrm{CaR}$ is expressed in the cells of juxtaglomerular apparatus in the kidney [39]. Activation of $\mathrm{CaR}$ in these cells seems to decrease the plasma renin activity as it has been shown in both in vitro and in vivo studies [40,31].

PTH stimulates the IL-6 synthesis and release. Elevated serum IL-6 contributes to the increase of CRP synthesis in the liver $[27,28]$. We hypothesized that treatment with cinacalcet may thus lower both IL-6 and CRP concentration through the decrease of serum PTH concentration. Moreover, parathyroidectomy was shown to decrease serum concentration of inflammation markers in patients with primary hyperparathyroidism $[41,42]$. It is well known that systemic inflammation participates in the pathogenesis of hypertension. However, in the current study no significant changes in either IL-6, or CRP concentrations were found after 6 months cinacalcet treatment. This is in agreement with the results published by Messa et al. In this study 6-month cinacalcet treatment didn't cause any changes in serum IL-6 concentrations [43]. Also the overall IL- 6 concentrations were similar those obtained in our patients.

Our study has some unavoidable drawbacks. One is the lack of placebo treated control group. Another one is the fact that we did not have data from ABPM measurements, but only from the clinical measurements, which may cause bias because of the intradialytic volume changes in maintenance haemodialysis patients. We recognize our study as a hypothesis generating one and hope to encourage the conduction of other clinical studies, hopefully with the use of ABPM.

\section{Conclusions}

In conclusion, we found that six-month treatment with cinacalcet decreases systolic BP in haemodialysed patients with chronic kidney disease and secondary hyperparathyroidism. The elucidation of exact pathomechanism of such a BP decrease needs further clinical studies, but it seems not to be related to inflammatory status changes.

None to declare.

\section{Conflict of Interests}

\section{Funding}

The study was the Department's statutory work.

\section{References}

1. Cunningham J., Locatelli F., Rodriguez M. Secondary hyperparathyroidism: pathogenesis, disease progression, and therapeutic options. Clin. J. Am. Soc. Nephrol. 2011; 6: 913-921.

2. Komaba H., Kakuta T., Fukagawa M. Diseases of the parathyroid gland in chronic kidney disease. Clin. Exp. Nephrol. 2011; 15: 797-809.

3. Wiecek A., Kuczera M., Ganten U., Ritz E., Mann J.F. Influence of parathyroidectomy on blood pressure and vascular reactivity in spontaneously hypertensive rats. Clin. Exp. Hypertens A. 1989; 11: 1515-1533.

4. Suzuki T., Yonemura K., Maruyama Y. et al. Impact of serum parathyroid hormone concentration and its regulatory factors on arterial stiffness in patients undergoing maintenance hemodialysis. Blood Purif 2004; 22: 293-297.

5. Zhao G., Ford E.S., Li C., Kris-Etherton P.M., Etherton T.D., Balluz L.S. Independent associations of serum concentrations of 25-hydroxyvitamin $\mathrm{D}$ and parathyroid hormone with blood pressure among US adults. J. Hypertens. 2010; 28: 1821-1828.

6. Bhuriya R, Li S, Chen SC, McCullough PA, Bakris GL. Plasma parathyroid hormone level and prevalent cardiovascular disease in CKD stages 3 and 4: an analysis from the Kidney Early Evaluation Program (KEEP). Am J Kidney Dis 2009; 53: 3-10.

7. Chan R., Chan D., Woo J. et al. Serum 25-hydroxyvitamin D and parathyroid hormone levels in relation to blood pressure in a cross-sectional study in older Chinese men. J. Hum. Hypertens. 2012; 26: 20-27.

8. Hagström E., Ingelsson E., Sundström J. et al. Plasma parathyroid hormone and risk of congestive heart failure in the community. Eur. J. Heart Fail. 2010; 12: 1186-1192.

9. Hagström E., Hellman P., Larsson T.E. et al. Plasma parathyroid hormone and the risk of cardiovascular mortality in the community. Circulation 2009; 119: 2765-2771.

10. Deo R., Katz R., Shlipak M.G. et al. Vitamin D, parathyroid hormone, and sudden cardiac death: results from the Cardiovascular Health Study. Hypertension 2011; 58: 1021-1028.

11. Nagano N. Pharmacological and clinical properties of calcimimetics: calcium receptor activators that afford an innovative approach to controlling hyperparathyroidism. Pharmacol. Ther. 2006; 109: 339-365.

12. Harrington P.E., Fotsch C. Calcium sensing receptor activators: calcimimetics. Curr. Med. Chem. 2007; 14: 3027-3034.

13. Vervloet M., Bencova V., Malberti F. et al. "Real-World" use of cinacalcet for managing SHPT in different European countries: analysis of data from the ECHO observational study. Clin. Nephrol. 2010; 74: 198-208.

14. Fishbane S., Shapiro W.B., Corry D.B. et al. Cinacalcet $\mathrm{HCl}$ and concurrent low-dose vitamin D improves treatment of secondary hyperparathyroidism in dialysis patients compared with vitamin 
D alone: the ACHIEVE study results. Clin. J. Am. Soc. Nephrol. 2008; 3: 1718-1725

15. Raggi P., Chertow G.M., Torres P.U. et al. The ADVANCE study: a randomized study to evaluate the effects of cinacalcet plus low-dose vitamin $\mathrm{D}$ on vascular calcification in patients on hemodialysis. Nephrol. Dial. Transplant. 2011; 26: 1327-1339.

16. Bernstein D.S., Pletka P., Hattner R.S., Hampers C.L., Merrill J.P. Effect of total parathyroidectomy and uremia on the chemical composition of bone, skin and aorta in the rat. Isr. J. Med. Sci. 1971; 7: 513-514.

17. Bogin E., Massry S.G., Harary I. Effect of parathyroid hormone on rat heart cells. J. Clin. Invest. 1981; 67: 1215-1227.

18. Vaziri N.D., Ni Z., Wang X.Q., Oveisi F., Zhou X.J. Downregulation of nitric oxide synthase in chronic renal insufficiency: role of excess PTH. Am. J. Physiol. 1998; 274: 642-649

19. Jorde R., Svartberg J., Sundsfiord J. Serum parathyroid hormone as a predictor of increase in systolic blood pressure in men. J. Hypertens. 2005; 23: 1639-1644.

20. Saleh F.N., Schirmer H., Sundsford J., Jorde R. Parathyroid hormone and left ventricular hypertrophy. Eur. Heart J. 2003; 24: 2054-2060.

21. Carrasco F.R., Pérez-Flores I., Calvo N., Ridao N., Sánchez A., Barrientos. Treatment of persistent hyperparathyroidism in renal transplant patients with cinacalcet improves control of blood pressure Transplant. Proc. 2009; 41: 2385-2387.

22. Rydberg E., Birgander M., Bondeson A.G., Bondeson L., Willenheimer R. Effect of successful parathyroidectomy on 24-hour ambulatory blood pressure in patients with primary hyperparathyroidism. Int. J. Cardiol. 2010; 142: 15-21.

23. Oberg B.P., McMenamin E., Lucas F.L. et al. Increased prevalence of oxidant stress and inflammation in patients with moderate to severe chronic kidney disease. Kidney Int. 2004; 65: 1009-1106.

24. Dounousi E., Papavasiliou E., Makedou A. et al. Oxidative stress is progressively enhanced with advancing stages of CKD. Am. J. Kidney Dis. 2006; 48: 752-760.

25. Tucker P.S., Scanlan A.T., Dalbo V.J. Chronic kidney disease influences multiple systems: describing the relationship between oxidative stress, inflammation, kidney damage, and concomitant disease. Oxid. Med. Cell Longev. 2015; doi: 10.1155/2015/806358.

26. Pecoits-Filho R., Heimbürger O., Bárány P. et al. Associations between circulating inflammatory markers and residual renal function in CRF patients. Am. J. Kidney Dis. 2003; 41: 1212-1218.

27. McCarty M.F. Secondary hyperparathyroidism promotes the acute phase response - a rationale for supplemental vitamin D in prevention of vascular events in the elderly. Med. Hypotheses 2005; 64: 1022-1026.

28. Castell J.V., Gómez-Lechón M.J., David M. et al. Interleukin-6 is the major regulator of acute phase protein synthesis in adult human hepatocytes. FEBS Lett 1989; 242: 237-239.

29. Grey A., Mitnick M.A., Masiukiewicz U. et al. A role for interleukin-6 in parathyroid hormone-induced bone resorption in vivo. Endocrinology 1999; 140: 4683-4690.
30. Bonet J., Bayés B., Fernández-Crespo P. et al. Cinacalcet may reduce arterial stiffness in patients with chronic renal disease and secondary hyperparathyroidism - results of a small-scale, prospective, observational study. Clin. Nephrol. 2011; 75: 181-187.

31. Atchison D.K., Ortiz-Capisano M.C., Beierwaltes W.H. Acute activation of the calcium-sensing receptor inhibits plasma renin activity in vivo. Am. J. Physiol. Regul. Integr. Comp. Physiol. 2010; 299: 1020-1026.

32. Dinh Q.N., Drummond G.R., Sobey C.G., Chrissobolis S. Roles of inflammation, oxidative stress, and vascular dysfunction in hypertension. Biomed. Res. Int. 2014; doi: 10.1155/2014/406960.

33. Sedighi O., Makhlough A., Kashi Z., Zahedi M. Relationship between serum parathyroid hormone and hypertension in hemodialysis patients. Iran J. Kidney Dis. 2011; 5: 267-270.

34. Bhuriya R., Li S., Chen S.C., McCullough P.A., Bakris G.L. Plasma parathyroid hormone level and prevalent cardiovascular disease in CKD stages 3 and 4: an analysis from the Kidney Early Evaluation Program (KEEP). Am. J. Kidney Dis. 2009; 53: 3-10.

35. Zhao G., Ford E.S., Li C., Kris-Etherton P.M., Etherton T.D., Balluz L.S. Independent associations of serum concentrations of 25-hydroxyvitamin D and parathyroid hormone with blood pressure among US adults. J. Hypertens. 2010; 28: 1821-1828.

36. Chan R., Chan D., Woo J. et al. Serum 25-hydroxyvitamin D and parathyroid hormone levels in relation to blood pressure in a cross-sectional study in older Chinese men. J. Hum. Hypertens. 2012; 26: 20-27.

37. Bonet J., Bayés B., Fernández-Crespo P. et al. Cinacalcet may reduce arterial stiffness in patients with chronic renal disease and secondary hyperparathyroidism - results of a small-scale, prospective, observational study. Clin. Nephrol. 2011; 75: 181-187.

38. Suzuki $\mathrm{H}$., Inoue T., Watanabe $\mathrm{Y}$. et al. Does cinacalcet $\mathrm{HCl}$, an oral calcimimetic agent for the treatment of secondary hyperparathyroidism, improve arterial stiffness in patients on continuous ambulatory peritoneal dialysis? Adv. Perit. Dial. 2011; 27: 134-139.

39. Ortiz-Capisano M.C., Ortiz P.A., Garvin J.L., Harding P., Beierwaltes W.H. Expression and function of the calcium-sensing receptor in juxtaglomerular cells. Hypertension 2007; 50: 737-743.

40. Ortiz-Capisano M.C., Liao T.D., Ortiz P.A., Beierwaltes W.H. Calcium-dependent phosphodiesterase $1 \mathrm{C}$ inhibits renin release from isolated juxtaglomerular cells. Am. J. Physiol. Regul. Integr. Comp. Physiol. 2009; 297: 1469-1276.

41. Guo C.Y., Holland P.A., Jackson B.F. et al. Immediate changes in biochemical markers of bone turnover and circulating interleukin- 6 after parathyroidectomy for primary hyperparathyroidism. Eur. J. Endocrinol. 2000; 142: 451-459.

42. Halabe A., Shohat B. Effect of parathyroid adenoma excision on interleukin-6 (IL-6) and IL-2 receptor levels. Metabolism 2000; 49: 192-194.

43. Messa P., Alberti L., Como G. et al. Calcimimetic increases osteoprotegerin and decreases fetuin-A levels in dialysis patients. Nephrol. Dial. Transplant. 2007; 22: 2724-2725. 